\title{
A Developed Graphical User Interface for Power System Stability and Robustness Studies
}

\author{
Ghouraf Djamel Eddine ${ }^{\star 1}$, Naceri Abdellatif ${ }^{2}$, Abid Mohamed, Kabi Wahiba ${ }^{3}$ \\ IRECOM Laboratory Department of Electrical Engineering University of SBA, BP 98 22000, SBA, Algeria \\ ${ }^{*}$ Corresponding author, e-mail: jamelbel22@yahoo.fr ${ }^{\top}$, abdnaceri@yahoo.fr ${ }^{2}$
}

\begin{abstract}
This paper present the realization and development of a graphical user interface (GUI) to studied the stability and robustness of power systems (analysis and synthesis), using Conventional Power System Stabilizers (CPSS - realized on PID scheme) or advanced controllers (based on adaptive and robust control), and applied on automatic excitation control of powerful synchronous generators, to improve dynamic performances and robustness. The GUI is a useful average to facilitate stability study of power system with the analysis and synthesis of regulators, and resolution of the compromise: results precision / calculation speed. The obtained Simulation results exploiting our developed GUI realized under MATLAB shown considerable improvements in static and dynamic performances, a great stability and enhancing the robustness of power system, with best precision and minimum operating time. This study was performed for different types of powerful synchronous generators.
\end{abstract}

Keywords: synchronous generators, AVR and PSS, analysis and synthesis, modelisation and simulation, GUI-Matlab, stability and robustness

Copyright $\odot 2015$ Institute of Advanced Engineering and Science. All rights reserved.

\section{Introduction}

Power system stability continues to be the subject of great interest for utility engineers and consumers alike and remains one of the most challenging problems facing the power community. The electric power system is a complex system with highly non-linear dynamics. Its stability depends on the operating conditions of the power system and its configuration. Low frequency oscillations are a common problem in large power systems. Excitation control or Automatic Voltage Regulator (AVR) is well known as an effective means to improve the overall stability of the power system. Power System Stabilizers (PSS) are added to excitation systems to enhance the damping during low frequency oscillations [1,2]. The output of the PSS is applied as a supplementary control signal to the machine voltage regulator terminal. Oscillations of small magnitude and low frequency often persist for long periods of time and in some cases can cause limitations on the power transfer capability.

GUI (graphical user interface) creates graphical display in one or more windows containing controls, called components that enable a user to perform interactive tasks. The user of the GUI does not have to create a script or type commands at the command line to accomplish the tasks [3,4]. Unlike coding programs to accomplish tasks, the user of a GUI need not understand the details of how the tasks are performed. The graphical user interface (GUI) can make the understanding of the effects of stability study of power system with the analysis and synthesis of regulators, and resolution of the compromise: results precision / calculation speed.

\section{Dynamic Power System Modelling}

2.1. Description of the Studied Power System

A single machine-infinite bus system (SMIB) is considered for the present investigation. A machine connected to a large system through a transmission line may be reduced to a SMIB system, by using the venin's equivalent of the transmission network external to the machine (Figure 1). The synchronous machine is described as the fourth order model. The two-axis synchronous machine representation with a field circuit in the direct axis but without damper windings is considered for the analysis. The system dynamics of the synchronous machine can 
be expressed as a set of four first order linear differential equations given in equations below [5].

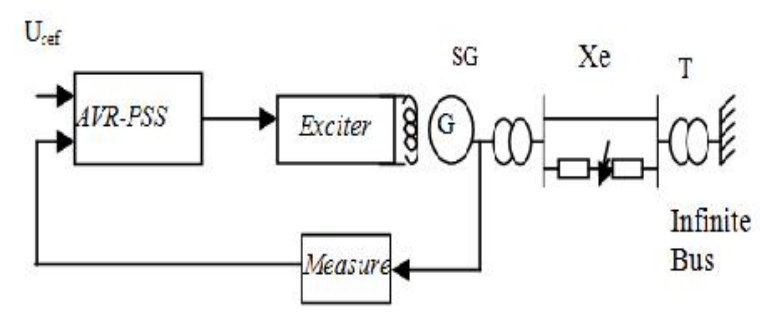

Figure 1. Standard system IEEE type SMIB with excitation control of SG

\subsection{Modeling of Synchronous Generators}

In this paper we based on the permeances networks modeling of Synchronous Generators for eliminate simplifying hypotheses and testing our control algorithm. The SG model is defined by equations 1 to 5 and the Figure $2[6]$ :

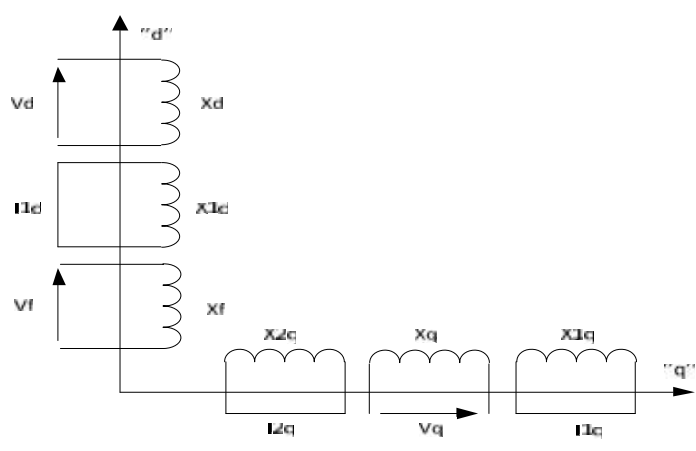

Figure 2. PARK Transformation of the synchronous machine

\section{a) Currents equations:}

$$
\begin{array}{ll}
I_{q}=\left(U_{q}-E_{q}^{\prime \prime}\right) / X_{d}^{\prime \prime} & I_{1 q}=\left(\Phi_{1 q}-\Phi_{a q}\right) / X_{s r l q} \\
I_{d}=-\left(U_{d}-E_{d}^{\prime \prime}\right) / X_{q}^{\prime \prime} & I_{2 q}=\left(\Phi_{2 q}-\Phi_{a q}\right) / X_{s r 2 q} \\
I_{1 d}=\left(\Phi_{1 d}-\Phi_{a d}\right) / X_{s r d} & I_{f}=\left(\Phi_{f}-\Phi_{a d}\right) / X_{s r} \\
E_{q}^{\prime \prime}=\frac{1 / X_{s f} \cdot \frac{X_{f}}{X_{a d}} E_{q}^{\prime}+1 / X_{s f d} \cdot \frac{X_{f d}}{X_{a d}} E_{f q}^{\prime}}{\frac{1}{X_{a d}}+\frac{1}{X_{s f}}+\frac{1}{X_{s f d}}} E_{d}^{\prime \prime}=\frac{1 / X_{s q q} \cdot \frac{X_{f q}}{X_{a q}} E_{f d}^{\prime}}{\frac{1}{X_{a d}}+\frac{1}{X_{s q q}}}
\end{array}
$$

b) Fields equations:

$$
\begin{aligned}
& \Phi_{a d}=E_{q}^{\prime \prime}+\left(X_{d}^{\prime \prime}-X_{s}\right) I_{d} ; \Phi_{a q}=E_{d}^{\prime \prime}+\left(X_{q}^{\prime \prime}-X_{s}\right) I_{q} \\
& \Phi_{1 q}=\omega_{s} \int_{0}^{\Phi_{1 q}}\left(-R_{1 q} I_{1 q}\right) \cdot d t \Phi_{2 q}=\omega_{s} \int_{0}^{\Phi_{2 q}}\left(-R_{2 q} I_{2 q}\right) \cdot d t \\
& \Phi_{f}=\omega_{s} \int_{0}^{\Phi_{f}}\left(-R_{f} I_{f}+U_{f 0}\right) d t \Phi_{1 d}=\omega_{s} \int_{0}^{\Phi_{1 d}}\left(-R_{1 d} I_{1 d}\right) \cdot d t
\end{aligned}
$$


c) Mechanical equations:

$$
\begin{aligned}
& d \delta=\left(\omega-\omega_{s}\right) d t \quad, \quad s=\frac{\omega-\omega_{s}}{\omega_{s}} \\
& M_{T}+M_{j}+M_{e}=0 \quad \text { avec } M_{j}: \text { moment d'inertie }\left(M_{j}=-j \frac{d \omega}{d t}\right) \\
& T_{j} \frac{d}{d t} s+\left(\Phi_{a d} . I_{q}-\Phi_{a q} \cdot I_{d}\right)=M_{T} \quad \text { ou } \quad T_{j} \frac{d}{d t} s=M_{T}-M_{e} j \frac{d \omega}{d t}+\frac{P_{e}}{\omega_{s}}=M_{T}
\end{aligned}
$$

\subsection{Model of the AVR}

The AVR (Automatic Voltage Regulator), is a controller of the PSG voltage that acts to control this voltage, thought the exciter .Furthermore, the PSS was developed to absorb the generator output voltage oscillations [1].

In our study the synchronous machine is equipped by a voltage regulator model "IEEE" type - $5[7,8]$, as is shown in Figure 3.

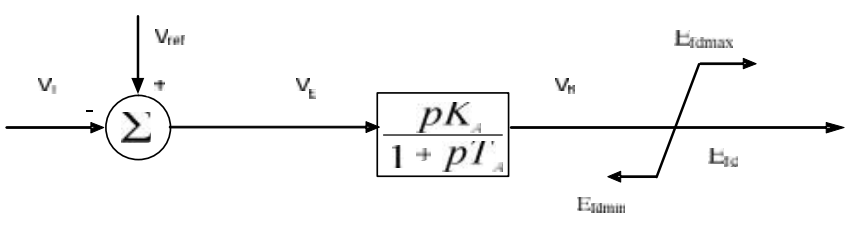

Figure 3. A simplified” IEEE type-5” AVR

$$
V_{R}=\frac{K_{A} V_{E}-V_{R}}{T_{A}} \quad, \quad V_{E}=V_{r e f}-V_{F}
$$

\subsection{Model of the convitional PSS}

The basic function of the Conventional PSS is to damp electromechanical oscillations. To achieve the damping, the CPSS proceeds by controlling the AVR excitation using auxiliary stabilizing signal. The CPSS's structure is illustrated in Figure 4 [9, 10].

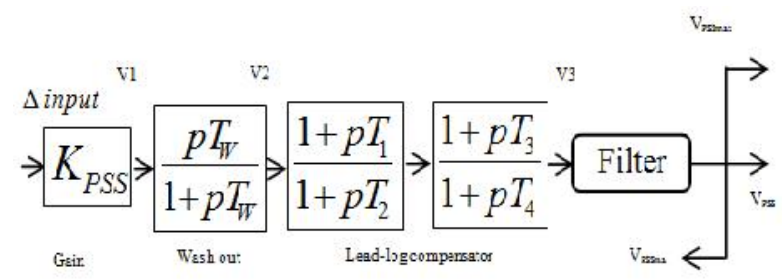

Figure 4. A functional diagram of the used CPSS

\subsubsection{The Gain}

The gain determines the amount of damping introduced by the stabilizer. Therefore, increasing the gain can move unstable oscillatory modes into the left - hand complex plane. Ideally, the gain should be set to a value corresponding to a maximum damping. However, in practice the gain Kpss is set to a value satisfactory to damp the critical mode without compromising the stability of other modes.

\subsubsection{Washout}

The washout stage is a High Pass Filter (HPF) with purpose to respond only to oscillations in speed and block the dc offsets. The Washout filter prevents the terminal voltage of the generator to drift away due to any steady change in speed. 


\subsubsection{Phase Compensation}

This stage consists of two lead - lag compensators as shown in Figure 5 (lead - lag compensation stage). The lead stage is used to compensate for the phase lag introduced by the AVR and the field circuit of the generator. The lead - lag parameters T1-T4 are tuned in such as way that speed oscillations give a damping torque on the rotor. When the terminal voltage is varied, the PSS affects the power flow from the generator, which efficiently damps the local modes.

\subsubsection{Torsional Filter}

This stage is added to reduce the impact on the torsional dynamics of the generator while preventing the voltage errors due to the frequency offset.

\subsubsection{Limiter}

The PSS output requires limits in order to prevent conflicts with AVR actions during load rejection. The AVR acts to reduce the terminal voltage while it increases the rotor speed and the bus frequency. Thus, the PSS is compelled to counteract and produce more positive output. As described in by P. Kundur in [7], the positive and negative limit should be around the AVR set point to avoid any counteraction. The positive limit of the PSS output voltage contributes to improve the transient stability in the first swing during a fault. The negative limit appears to be very important during the back swing of the rotor.

\subsubsection{Input Single of the CPSS}

The input signals include deviations in the rotor speed $\left(\omega=\omega_{\text {mech }}-\omega o\right)$, the frequency $(\mathrm{f})$, the electrical power $(\mathrm{Pe})$ and the accelerating power $(\mathrm{Pa})$

In this paper the PSS signal used, is given by [5]:

$$
\begin{aligned}
& \dot{V}_{1}=\frac{V_{2}-V_{1}}{T_{1}}+\frac{T_{2}}{T_{1}} \dot{V}_{2} ; \\
& \dot{V}_{2}=\frac{V_{3}-V_{2}}{T_{2}}+\frac{T_{3}}{T_{2}} \dot{V}_{2} ; \\
& \dot{V}_{3}=\frac{V_{3}}{T_{W}} \dot{V}_{1} ; \dot{V}_{1}=K_{\text {PSS }} \cdot \Delta \text { input } \quad \Delta \text { input }=\left\{\begin{array}{l}
\Delta P, \int p \\
\text { or } \\
\Delta \omega=\omega_{\text {math }}-\omega_{0} \\
\text { and } \\
\Delta I_{f}=I_{f}-I_{f 0} \\
\text { and } \\
\Delta U_{f}=U_{f}-U_{f 0}
\end{array}\right.
\end{aligned}
$$

\section{Calculated code under MATLAB / SIMULINK}

The "SMIB" system used in our study includes:

a) A powerful synchronous generator (PSG);

b) The voltage regulator AVR and Power System Stabilizer AVR-PSS;

c) A Power Infinite network line.

We used for our simulation in this paper, the SMIB mathematical model based on permeances networks model (called Park-Gariov), and shown in Figure 5 [11]:

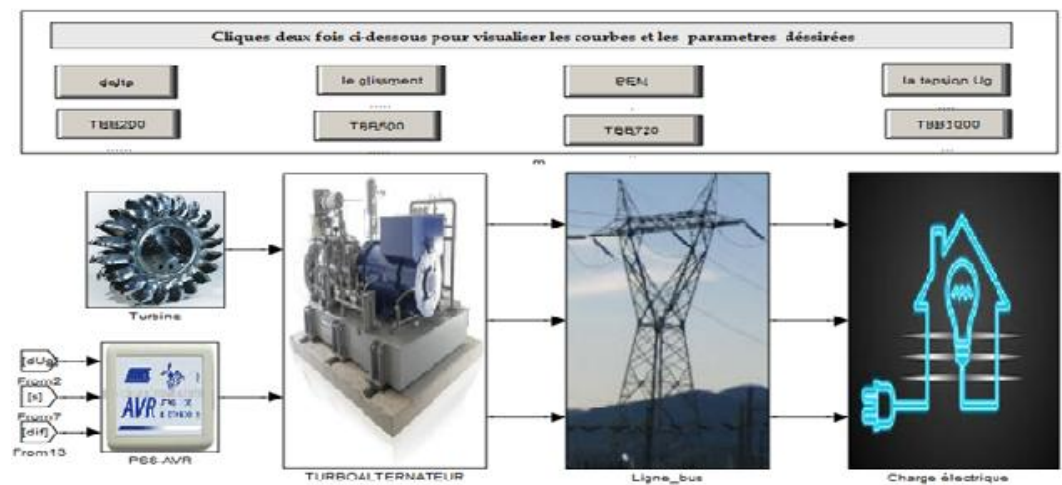

Figure 5. Structure of the synchronous generator (PARK-GARIOV model) with the excitation controller 


\section{The Simulation Result Under GUI/ Matlab}

GUIDE, the MATLAB graphical user interface development environment, provides a set of tools for creating graphical user interfaces (GUIs). These tools greatly simplify the process of designing and building GUIs. You can use the GUIDE tools to perform the following tasks:

\subsection{Lay out the GUI.}

Using the GUIDE Layout Editor, you can lay out a GUI easily by clicking and dragging GUI components-such as panels, buttons, text fields, sliders, menus, and so on-into the layout area. GUIDE stores the GUI layout in a FIG-file.

\subsection{Program the GUI}

"GUIDE automatically generates a MATLAB program file that controls how the GUI operates. The code in that file initializes the GUI and includes function templates for the most commonly used callbacks for each component-the commands that execute when a user clicks a GUI component. Using the MATLAB editor, you can add code to the callbacks to perform the functions you want.

\subsection{Starting GUIDE}

Start GUIDE by typing guide at the MATLAB command prompt. This command displays the GUIDE Quick Start dialog box, as shown in the following Figure 6.

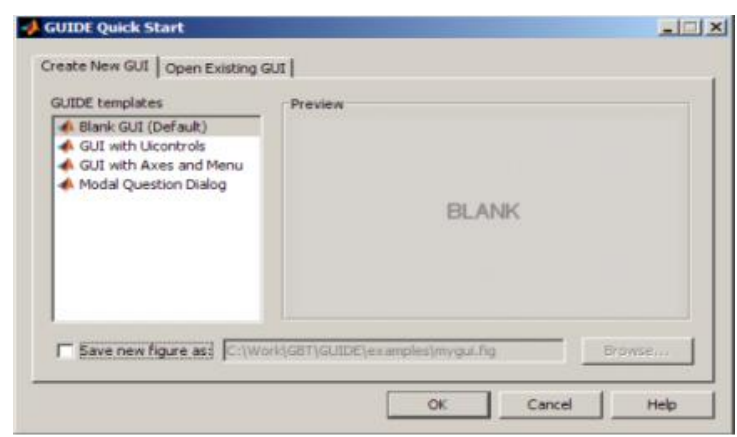

Figure 6. The GUIDE Quick Start dialog box

From the GUIDE Quick Start dialog box, you can perform the following tasks:

a) Create a new GUI from one of the GUIDE templates prebuilt GUIs that you can modify for your own purposes.

b) Open an existing GUI.

\subsection{The Layout Editor}

When we open a GUI in GUIDE, it is displayed in the Layout Editor, which is the control panel for all of the GUIDE tools. The following figure shows the Layout Editor with a blank GUI template.

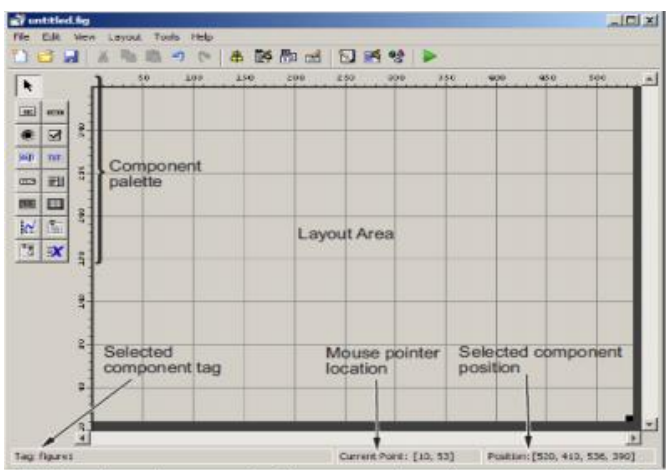

Figure 7. The Layout EditorImplementation under the realized GUI - Matlab Interfcace

TELKOMNIKA Vol. 15, No. 3, September 2015: $458-467$ 


\section{Implementation under the realized GUI - Matlab Interface}

To performed different operations (analysis - synthesis) and to visualized the different static and dynamic behaviors we have realized and developed a graphical Interface "GUI" under MATLAB. This Interface allows as to:

a) Improves human - computer interaction;

b) Perform control system from PSS controller;

c) Quick View of the system regulation results and simulation;

d) Calculate the system dynamic parameters ;

e) Test the system stability and its robustness;

f) Study the different operating regime (under-excited, rated and over excited regime for example).

g) Exploitation of the different conventional (PI, PID), and/or advanced control techniques (optimal, adaptive and robust).

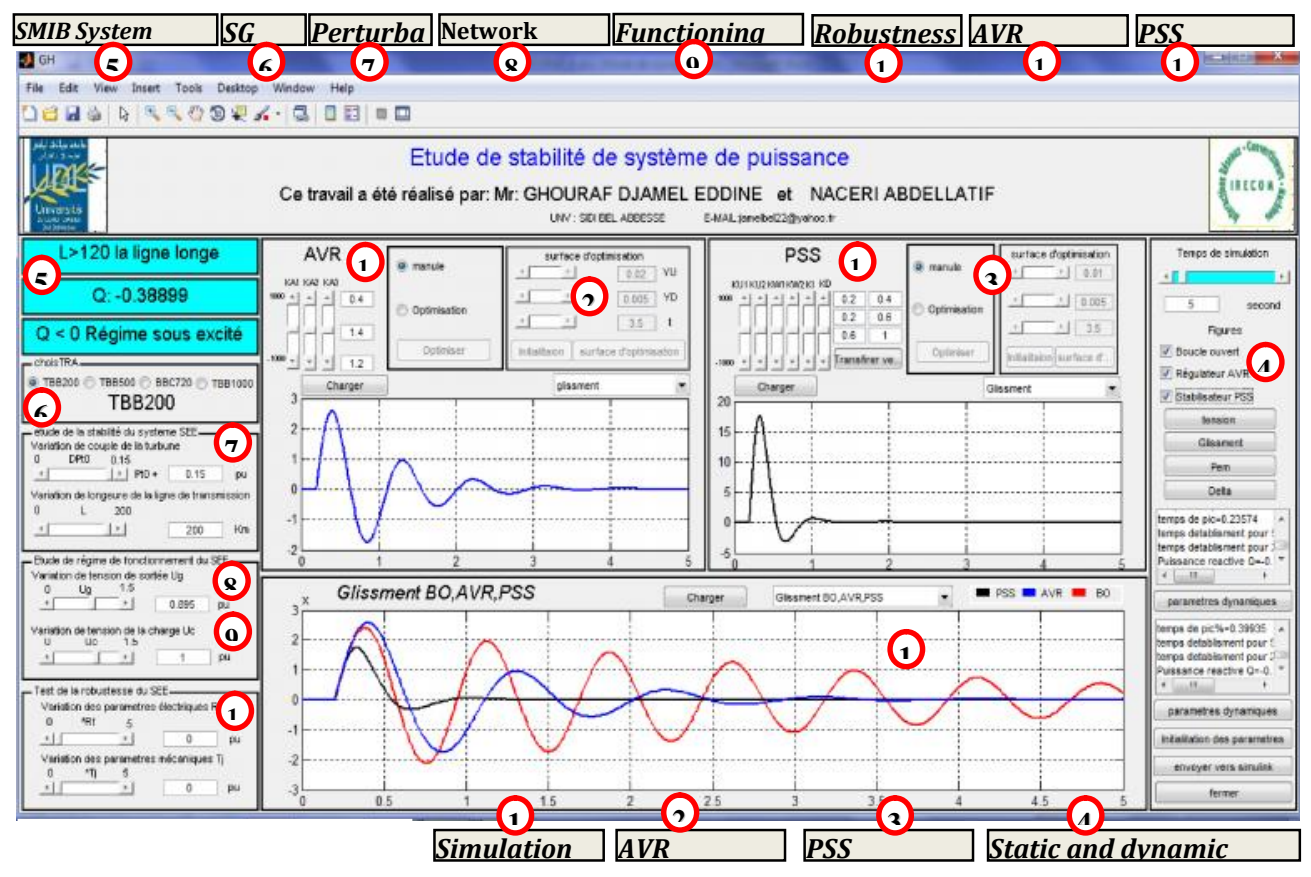

Figure 8. The developed graphical interface GUI under MATLAB

\subsection{Simulation Results and Discussion}

The Stability study of the SMIB system was performed by mechanical perturbation (variation of turbine torque $\mathrm{Tm}$ of $15 \%$ at $\mathrm{t}=0.2 \mathrm{~s}$ ).

The following results (Table 1 and Figure 10-13) were obtained using our developed graphical interface under Matlab in this paper, by studying the SMIB static and dynamic performances in the following cases:

a) The Open Loop (OL) without regulation;

b) Closed Loop System with AVR;

c) Closed Loop with the conventional stabilizer CPSS.

We have simulated three functioning mode of the used generators: under-excited, nominal and over-excited modes.

Our study interested different synchronous generators types [11]: TBB-200, TBB-500 BBC-720, TBB-1000 (the parameters shown in Appendix).

Table 1 presents the simulation results of static and dynamic performances applied on powerful synchronous generators in $\mathrm{CL}$ and $\mathrm{OL}$ for an average line $\mathrm{Xe}=0.3 \mathrm{pu}$, and active power $\mathrm{P}=0.85$ p.u.

With:

$\alpha$ : Damping coefficient; $\varepsilon \%$ : the static error,

$d \%$ : the maximum overshoot; $t_{s}$ : the setting time 
Figures 10 to 13 show obtained simulation results, with:

(a): the interior angle 'delta'; (b): the electromagnetic power system 'Pe';

(c): speed deviation in \%'s'; (d): the stator terminal voltage 'Ug'.

The electromechanical damping oscillations of synchronous generators parameters in under-excited mode with OL (green) and the controllable power system equipped by PSS (Black) and AVR (Bleu) are given in figures 9 to 10. The stability Study of simulation results, it can be observed that the use of PSS improves considerably the dynamic performances (static errors negligible so better precision), and very short setting time so very fast system (table 1), and we found that after few oscillations, the system returns to its equilibrium state even in critical situations (the under-excited regime) and granted the stability of the studied SMIB system.

Table 1. the "SMIB "static and dynamic performances

\begin{tabular}{|c|c|c|c|c|c|c|c|c|c|c|c|c|}
\hline \multicolumn{13}{|c|}{ SG No 1: TBB-200 (200 MW) } \\
\hline \multicolumn{4}{|c|}{ Damping coefficient $\alpha$} & \multicolumn{3}{|c|}{ static error \% } & \multicolumn{3}{|c|}{ The setting time for $5 \%$} & \multicolumn{3}{|c|}{ maximum overshoot \% } \\
\hline $\mathbf{Q}(\mathbf{p u})$ & OL & AVR & PSS & OL & AVR & PSS & OL & AVR & PSS & $\mathbf{O L}$ & AVR & PSS \\
\hline-0.1801 & $\begin{array}{c}\text { instabl } \\
\mathrm{e}\end{array}$ & -0.709 & -1.761 & $\begin{array}{c}\text { instabl } \\
\mathrm{e}\end{array}$ & -2.640 & -1.620 & $\begin{array}{c}\text { instabl } \\
\mathrm{e}\end{array}$ & 4,231 & 1,704 & 9.572 & $\begin{array}{c}9,05 \\
3\end{array}$ & 7,892 \\
\hline-0.2016 & $\begin{array}{c}\text { instabl } \\
\mathbf{e}\end{array}$ & -0.708 & -1.751 & $\begin{array}{c}\text { instabl } \\
\mathrm{e}\end{array}$ & -2.673 & -1.629 & $\begin{array}{c}\text { instabl } \\
\mathrm{e}\end{array}$ & 4,237 & 1,713 & 9.487 & $\begin{array}{c}9,03 \\
6\end{array}$ & 7,847 \\
\hline 0.1896 & -0.2442 & -0.791 & -1.855 & -5.038 & -2.269 & -1.487 & - & 3,793 & 1,617 & 10,959 & $\begin{array}{c}9,44 \\
7\end{array}$ & 8,314 \\
\hline 0.2847 & -0.2354 & -0.634 & -1.759 & -5.202 & -1.807 & -1.235 & - & 4,732 & 1,706 & 10,564 & $\begin{array}{c}8,77 \\
8\end{array}$ & $\mathbf{7 , 8 8 3}$ \\
\hline 0.6896 & -0.2095 & -0.403 & -1.470 & -3.777 & -0.933 & -0.687 & 14,320 & 7,444 & 2,041 & 9,402 & $\begin{array}{c}6,85 \\
1\end{array}$ & 6,588 \\
\hline 0.7173 & -0.2080 & -0.396 & -1.442 & -3.597 & -0.900 & -0.656 & 14,423 & 7,576 & 2,080 & 9,335 & $\begin{array}{c}6,73 \\
2\end{array}$ & 6,463 \\
\hline \multicolumn{13}{|c|}{ SG No 2: TBB-500 (500 MW) } \\
\hline \multicolumn{4}{|c|}{ Damping coefficient $\alpha$} & \multicolumn{3}{|c|}{ static error \% } & \multicolumn{3}{|c|}{ The setting time for $5 \%$} & \multicolumn{3}{|c|}{ maximum overshoot $\%$} \\
\hline $\mathbf{Q}(\mathbf{p u})$ & OL & AVR & PSS & OL & AVR & PSS & OL & AVR & PSS & $\mathbf{O L}$ & AVR & PSS \\
\hline-0.1801 & $\begin{array}{c}\text { instabl } \\
\mathrm{e}\end{array}$ & -0.765 & -1.956 & $\begin{array}{c}\text { instabl } \\
\mathrm{e}\end{array}$ & -4.197 & -1.459 & $\begin{array}{c}\text { instabl } \\
\mathrm{e}\end{array}$ & 3,922 & 1,534 & 9.458 & 9,405 & 8,766 \\
\hline-0.2016 & $\begin{array}{c}\text { instabl } \\
\mathrm{e}\end{array}$ & -0.758 & -1.926 & $\begin{array}{c}\text { instabl } \\
\mathrm{e}\end{array}$ & -4.230 & -1.461 & $\begin{array}{c}\text { instabl } \\
\mathrm{e}\end{array}$ & 3,958 & 1,558 & 9.254 & 9,137 & 8,632 \\
\hline 0.1896 & -0.2061 & -0.761 & -1.966 & -5.933 & -3.460 & -1.386 & - & 3,942 & 1,526 & 9,249 & 9,635 & 8,811 \\
\hline 0.2847 & -0.2245 & -0.691 & -1.850 & -5.802 & -2.525 & -1.170 & - & 4,342 & 1,621 & 9,075 & $\mathbf{9 , 5 0 0}$ & 8,292 \\
\hline 0.6896 & -0.3577 & -0.492 & -1.412 & -4.903 & -1.205 & -0.659 & 8,387 & 6,098 & 2,125 & 8,053 & 7,380 & 6,328 \\
\hline 0.7173 & -0.3660 & -0.484 & -1.401 & -4.597 & -1.157 & -0.683 & 8,197 & 6,198 & 2,141 & 7,426 & 7,260 & 6,279 \\
\hline \multicolumn{13}{|c|}{ SG 3: BBC-720 (720 MW) } \\
\hline \multicolumn{4}{|c|}{ Damping coefficient $\alpha$} & \multicolumn{3}{|c|}{ static error \% } & \multicolumn{3}{|c|}{ The setting time for $5 \%$} & \multicolumn{3}{|c|}{ maximum overshoot \% } \\
\hline $\mathbf{Q}(\mathbf{p u})$ & OL & AVR & PSS & OL & AVR & PSS & OL & AVR & PSS & $\mathbf{O L}$ & AVR & PSS \\
\hline-0.2202 & $\begin{array}{c}\text { instabl } \\
\mathrm{e}\end{array}$ & -0.736 & -1.858 & $\begin{array}{c}\text { instabl } \\
\mathrm{e}\end{array}$ & -2.640 & -1.577 & $\begin{array}{c}\text { instabl } \\
\mathrm{e}\end{array}$ & 4,076 & 1,349 & 9.956 & 9,776 & 8,955 \\
\hline-0.2464 & $\begin{array}{c}\text { instabl } \\
\mathbf{e}\end{array}$ & -0.728 & -1.818 & $\begin{array}{c}\text { instabl } \\
\mathrm{e}\end{array}$ & -2.673 & -1.579 & $\begin{array}{c}\text { instabl } \\
\mathrm{e}\end{array}$ & 4,121 & 1,323 & 9.935 & 9,648 & 8,762 \\
\hline 0.1489 & -0.2810 & -0.790 & -2.049 & -6.350 & -2.269 & -1.496 & - & 3,797 & 1,408 & 10,717 & 9,964 & 9,876 \\
\hline 0.2726 & -0.2651 & -0.714 & -2.017 & -6.260 & -1.807 & -1.262 & - & 4,202 & 1,630 & 10,110 & 9,424 & 8,721 \\
\hline 0.6552 & -0.2377 & -0.428 & -1.704 & -5.058 & -0.933 & -0.783 & 14,118 & 7,009 & 1,877 & 9,065 & 7,848 & 7,213 \\
\hline 0.6892 & -0.2365 & -0.421 & -1.398 & -4.617 & -0.900 & -0.758 & 14,218 & 7,126 & 1,801 & 9,020 & 7,736 & 6,738 \\
\hline \multicolumn{13}{|c|}{ SG 4: TBB-1000 (1000 MW) } \\
\hline \multicolumn{4}{|c|}{ Damping coefficient $\alpha$} & \multicolumn{3}{|c|}{ static error \% } & \multicolumn{3}{|c|}{ The setting time for $5 \%$} & \multicolumn{3}{|c|}{ maximum overshoot \% } \\
\hline $\mathbf{Q}(\mathbf{p u})$ & OL & AVR & PSS & OL & AVR & PSS & OL & AVR & PSS & OL & AVR & PSS \\
\hline-0.160 & $\begin{array}{c}\text { instabl } \\
\mathrm{e}\end{array}$ & -0.766 & -1.761 & $\begin{array}{c}\text { instabl } \\
\mathrm{e}\end{array}$ & -2.302 & -1.530 & $\begin{array}{c}\text { instabl } \\
\mathrm{e}\end{array}$ & 3,916 & 1,704 & 9.456 & 8,490 & 7,892 \\
\hline-0.222 & $\begin{array}{c}\text { instabl } \\
\mathrm{e}\end{array}$ & -0.762 & -1.731 & $\begin{array}{c}\text { instabl } \\
\mathrm{e}\end{array}$ & -3.787 & -1.517 & $\begin{array}{c}\text { instabl } \\
\mathrm{e}\end{array}$ & 3,937 & 1,713 & 9.412 & 8,430 & $\mathbf{7 , 8 4 7}$ \\
\hline 0.2139 & -0.2442 & -0.785 & -1.855 & -5.214 & -3.195 & -1.432 & - & 3,822 & 1,617 & 10,127 & 8,775 & 8,314 \\
\hline 0.1634 & -0.2354 & -0.677 & -1.759 & -5.111 & -2.565 & -1.222 & - & 4,431 & 1,706 & 10,342 & 8,155 & $\mathbf{7 , 8 8 3}$ \\
\hline 0.5746 & -0.2095 & -0.444 & -1.470 & -3.711 & -1.312 & -0.701 & 14,000 & 6,757 & 2,041 & 9,127 & 6,660 & 6,588 \\
\hline 0.5663 & -0.2080 & -0.433 & -1.442 & -3.432 & -1.266 & -0.665 & 14,675 & 6,928 & 2,080 & 9,428 & 6,495 & 6,463 \\
\hline
\end{tabular}

TELKOMNIKA Vol. 15, No. 3, September $2015: 458-467$ 


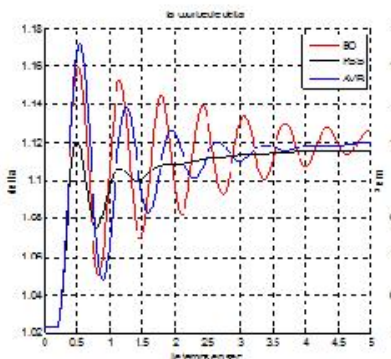

(a)

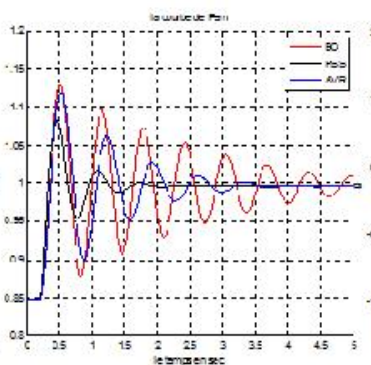

(b)

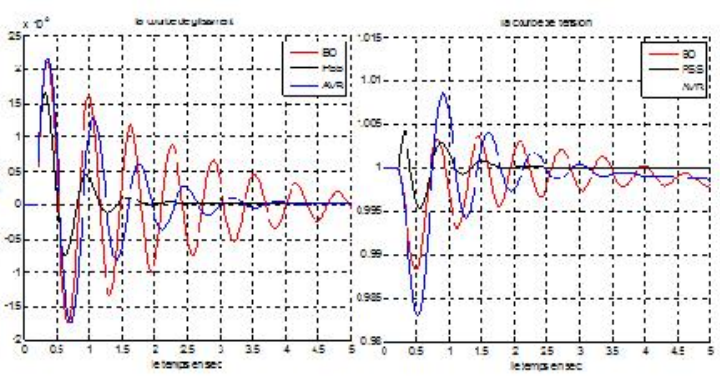

(c)

(d)

Figure 9. Under-excited Functioning system (TBB-200) connected to a long line with AVR, PSS and OL

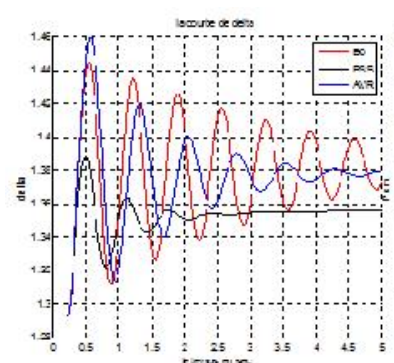

(a)

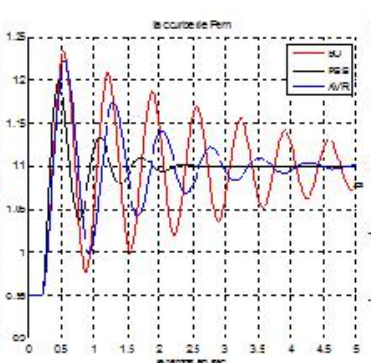

(b)

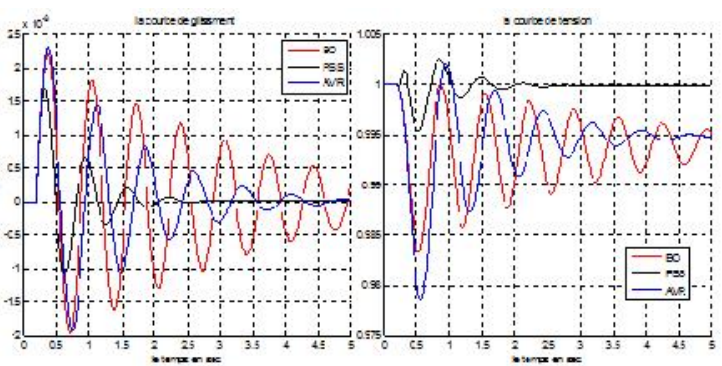

(c)

(d)

Figure10. under-excited Functioning system (TBB- 500) connected to a long line with AVR, PSS and OL

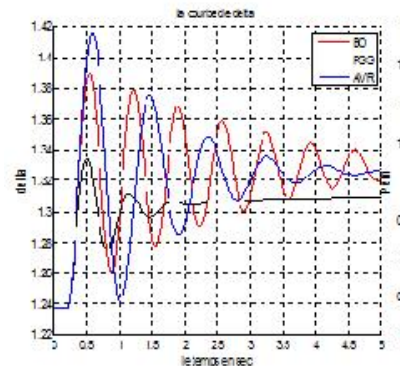

(a)

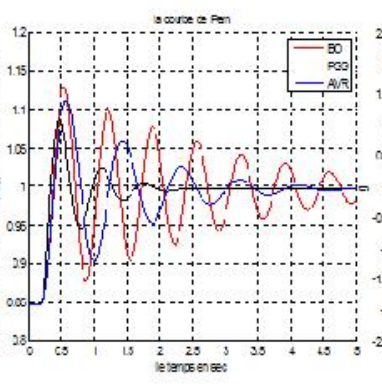

(b)

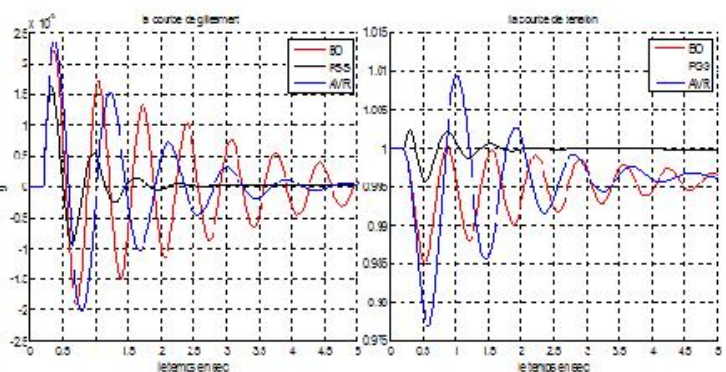

(c)

(d)

Figure 11. under-excited Functioning system (BBC-720) connected to a long line with AVR , PSS and OL

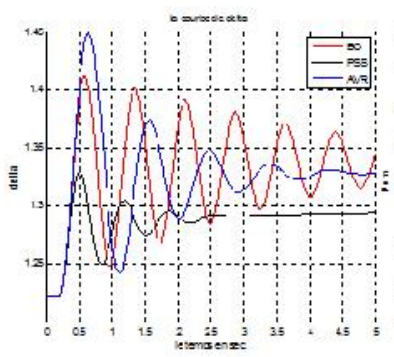

(a)

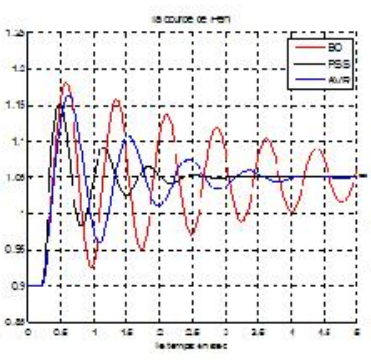

(b)

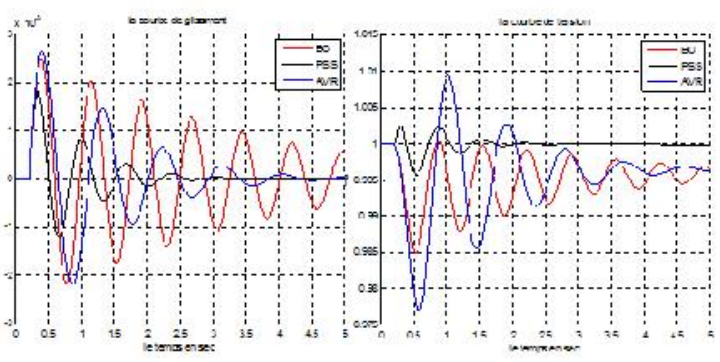

(c)

(d)

Figure 12. under-excited Functioning system in (TBB-1000) connected to a long line with AVR, PSS and OL 


\section{Conclusion}

The computer simulation results obtained by the realized GUI have proved a high efficiency of PSS, in comparison using AVR, showing stable system responses almost insensitive under different modes of the station. This PSS controller has the capability to improve its performance over time by interaction with its environment. In This paper we proposed and developed a graphical user interface 'GUI' under Matlab software, for acceleration and improvement the transient stability study of power system applied for powerful synchronous generators (analysis and synthesis), with an improved precision of the simulation results and the minimum operating time. Note that, our developed GUI was exploited and applied for other study (stability and robustness) using advanced adaptive and robust Controllers. As Perspective of the work, the implementation of our realized interface 'GUI' with a real-time simulation.

\section{References}

[1] LA Grouzdev, AA Starodebsev, SM Oustinov. Conditions d'application des meilleurs amortissements des processus transitoires dans les systèmes énergétiques avec optimisation numérique des paramètres du régulateur AVR-FA. Energie. 1990: 21-25.

[2] Demello FP, Flannett LN, Undrill JM. Practical approach to supplementary stabilizing from accelerating power. IEEE Trans. on PAS. 1978; PAS-97: 1515-1522.

[3] Xuebing Yang. Graphic User Interface Modelling and Testing Automation. School of Engineering and Science Victoria University. 2011.

[4] Howard Silver. Creating Graphical User Interfaces with MATLAB. Proceedings of the spring 2013 MidAtlantic Section Conference of the American Society of Engineering Education. 2013.

[5] Demello FP, Concordia C. Concepts of synchronous machine stability as affected by excitation control. IEEE Trans. on PAS. 1969; PAS-88: 316-329.

[6] Cuk Supriyadi Ali Nandar. Design of Robust Power System Stabilizer Considering Less Control Energy. International Journal of Power Electronics and Drive Systems IJPEDS. 2012; 2(1): 99-106.

[7] SV Smolovik. Méthodes de modélisation mathématique des processus transitoires des générateurs synchrones plus usuels et non traditionnels dans les systèmes électro -énergétiques. Thèse doctorat d'état, Institut polytechnique de Leningrad; 1988.

[8] P Kundur. Definition and Classification of power System Stability. Draft 2. 2002.

[9] PM Anderson, AA Fouad. Power System control and Stability. IEE Press. 1991.

[10] P Pavan Kumar, M Ravindra Babu, Saraswathi. Dynamic analysis of Single Machine Infinite Bus system using Single input and Dual input PSS. International Electrical Engineering Journal (IEEJ). 2012; 3(2): 632-641.

[11] Hong YY, Wu WC. A new approach using optimization for tuning parameters of power system stabilizers. IEEE Transactions on Energy Conversion. 1999; 14(3): 780-786.

[12] K Suryasen, KV Devadas, Harish A. GUI based Testing Tool for Transformer. International Journal of Electrical and Computer Engineering (IJECE). 2014; 4(3): 359-365.

[13] Ghouraf DE. Study and Application of the advanced frequency control techniques in the voltage automatic regulator of Synchronous machines. Magister Thesis. French: UDL-SBA; 2010.

[14] The Math Works, Inc. GUIDE quick start. 2008.

\section{Appendix}

1. Parameters of the used Turbo -Alternators

\begin{tabular}{|c|c|c|c|c|c|}
\hline Parameters & $\begin{array}{c}\text { TBB- } \\
200\end{array}$ & $\begin{array}{c}\text { TBB- } \\
500\end{array}$ & BBC-720 & TBB1000 & Units of measure \\
\hline $\begin{array}{c}\text { power } \\
\text { nominal }\end{array}$ & 200 & 500 & 720 & 1000 & MW \\
\hline $\begin{array}{c}\text { Factor of } \\
\text { power } \\
\text { nominal }\end{array}$ & 0.85 & 0.85 & 0.85 & 0.9 & p.u. \\
\hline$X_{d}$ & 2.56 & 1.869 & 2.67 & 2.35 & p.u. \\
\hline$X_{q}$ & 2.56 & 1.5 & 2.535 & 2.24 & p.u. \\
\hline$X_{s}$ & 0.222 & 0.194 & 0.22 & 0.32 & p.u. \\
\hline$X_{f}$ & 2.458 & 1.79 & 2.587 & 2.173 & p.u. \\
\hline$X_{s f}$ & 0.12 & 0.115 & 0.137 & 0.143 & p.u. \\
\hline
\end{tabular}




\begin{tabular}{|c|c|c|c|c|c|}
\hline$X_{s f d}$ & 0.0996 & 0.063 & 0.1114 & 0.148 & p.u. \\
\hline$X_{s f 1 q}$ & 0.131 & 0.0407 & 0.944 & 0.263 & p.u. \\
\hline$X_{s f 2 q}$ & 0.9415 & 0.0407 & 0.104 & 0.104 & p.u. \\
\hline$R_{a}$ & 0.0055 & 0.0055 & 0.0055 & 0.005 & p.u. \\
\hline$R_{f}$ & $\begin{array}{c}0.00084 \\
4\end{array}$ & $\begin{array}{c}0.00084 \\
4\end{array}$ & 0.00176 & 0.00132 & p.u. \\
\hline$R_{1 d}$ & 0.0481 & 0.0481 & 0.003688 & 0.002 & p.u. \\
\hline$R_{1 q}$ & 0.061 & 0.061 & 0.00277 & 0.023 & p.u. \\
\hline$R_{2 q}$ & 0.115 & 0.115 & 0.00277 & 0.023 & p.u. \\
\hline
\end{tabular}

2. Dynamics parameters calculated using realized GUI-MATLAB

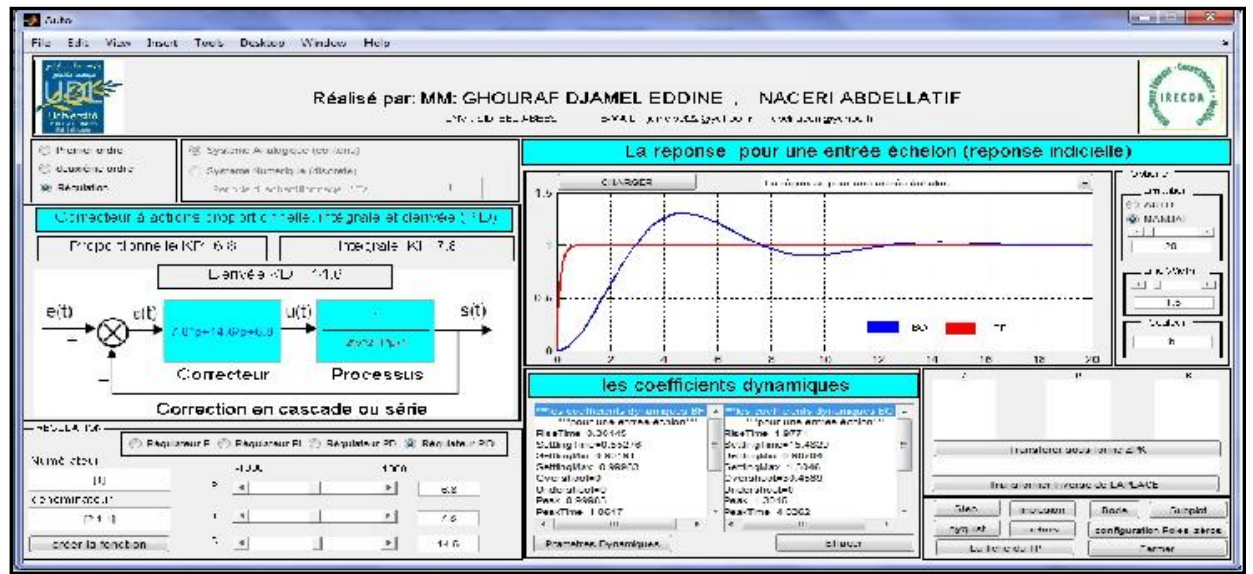

3. The system regulation results and simulation under $r+$ ealized GUI-MATLAB

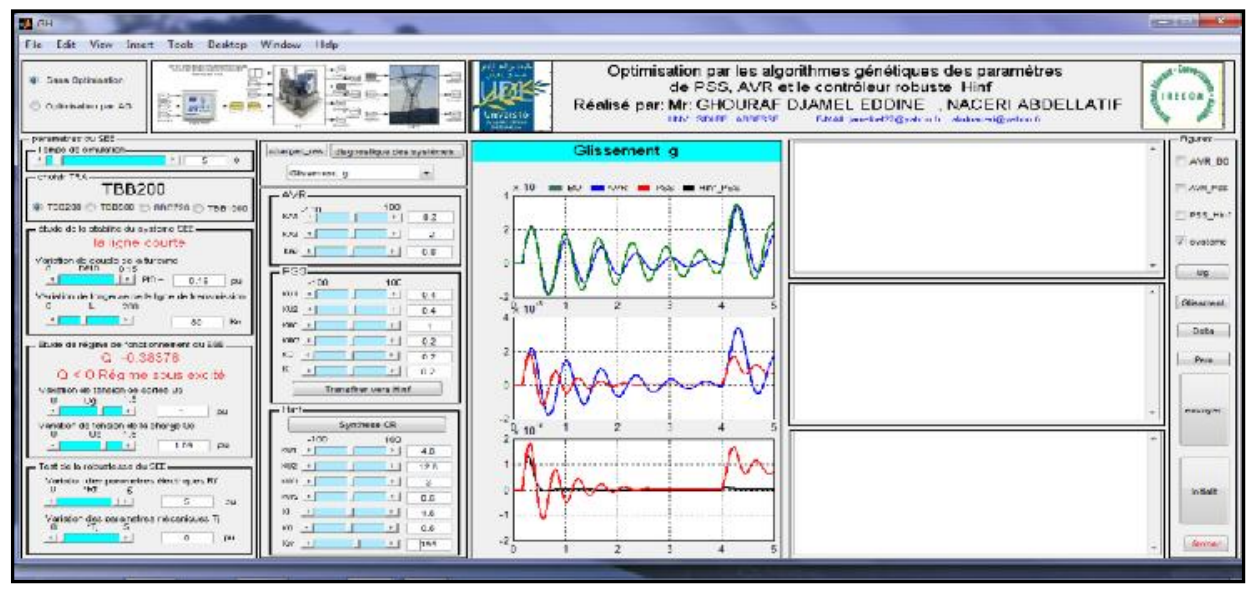

